Plants in Human Health and Nutrition Policy 


\section{World Review of Nutrition and Dietetics}

\section{Vol. 91}

Series Editor

Artemis P. Simopoulos

The Center for Genetics, Nutrition and Health, Washington, D.C., USA

Advisory Board

Regina C. Casper USA

Victor A. Rogozkin Russia

Ji Di Chen China

Leonard Storlien Sweden

Claudio Galli Italy

Ricardo Uauy-Dagach Chile

Uri Goldbourt Israel

Antonio Velazquez Mexico

C. Gopalan India

Mark L. Wahlqvist Australia

Tomohito Hamazaki Japan

Paul Walter Switzerland

Michel de Lorgeril France

Bruce A. Watkins USA 


\section{Plants in Human Health and Nutrition Policy}

Volume Editors

Artemis P. Simopoulos

The Center for Genetics, Nutrition and Health, Washington, D.C., USA

C. Gopalan

Nutrition Foundation of India, New Delhi, India

15 figures, 12 in color, and 40 tables, 2003

KARGER $\begin{aligned} & \text { Basel } \cdot \text { Freiburg } \cdot \text { Paris } \cdot \text { London } \cdot \text { New York } \\ & \text { Bangalore } \cdot \text { Bangkok } \cdot \text { Singapore } \cdot \text { Tokyo } \cdot \text { Sydney }\end{aligned}$ 


\section{Artemis P. Simopoulos}

The Center for Genetics,

Nutrition and Health

Washington, D.C. (USA)

\section{Gopalan}

Nutrition Foundation of India

New Delhi (India)

Library of Congress Cataloging-in-Publication Data

(CIP-Code is available from the Library of Congress on request)

Bibliographic Indices. This publication is listed in bibliographic services, including Current Contents ${ }^{\circledR}$ and Index Medicus.

Drug Dosage. The authors and the publisher have exerted every effort to ensure that drug selection and dosage set forth in this text are in accord with current recommendations and practice at the time of publication. However, in view of ongoing research, changes in government regulations, and the constant flow of information relating to drug therapy and drug reactions, the reader is urged to check the package insert for each drug for any change in indications and dosage and for added warnings and precautions. This is particularly important when the recommended agent is a new and/or infrequently employed drug.

All rights reserved. No part of this publication may be translated into other languages, reproduced or utilized in any form or by any means, electronic or mechanical, including photocopying, recording, microcopying, or by any information storage and retrieval system, without permission in writing from the publisher.

(C) Copyright 2003 by S. Karger AG, P.O. Box, CH-4009 Basel (Switzerland)

www.karger.com

Printed in Switzerland on acid-free paper by Reinhardt Druck, Basel

ISSN 0084-2230

ISBN 3-8055-7554-8 


\section{Contents}

VII Preface

1 Nutritional Composition of Molokhia (Corchorus olitorius) and Stamnagathi (Cichorium spinosum)

Zeghichi, S.; Kallithraka, S. (Crete); Simopoulos, A.P. (Washington, D.C.)

22 Nutritional Composition of Selected Wild Plants in the Diet of Crete Zeghichi, S; Kallithraka, S. (Crete); Simopoulos, A.P. (Washington, D.C.); Kypriotakis, Z. (Iraklio, Crete)

41 Kanjero (Digera arvensis) and Drumstick Leaves (Moringa oleifera): Nutrient Profile and Potential for Human Consumption Seshadri, S.; Nambiar, V.S. (Vadodara)

60 Ivy Gourd (Coccinia grandis Voigt, Coccinia cordifolia, Coccinia indica) in Human Nutrition and Traditional Applications

Wasantwisut, E.; Viriyapanich, T. (Nakhon Pathom)

67 Acerola (Malpighia glabra L., M. punicifolia L., M. emarginata D.C.): Agriculture, Production and Nutrition

Johnson, P.D. (Lakeview, Calif.)

76 Food-Based Approaches to Prevent and Control Micronutrient Malnutrition: Scientific Evidence and Policy Implications

Gopalan, C.; Tamber, B. (New Delhi)

132 Author Index

133 Subject Index 


\section{Preface}

This volume on Plants in Human Health and Nutrition Policy is the third volume in the series of World Review of Nutrition and Dietetics on the contribution of wild plants to human health and the metabolic consequences of changing dietary patterns $[1,2]$.

Consumption of fruits and vegetables has been associated with protection against various diseases, including cardiovascular, cerebrovascular disease and cancer. It is not known for certain what active dietary constituents contribute to the beneficial effects, but it is often assumed that antioxidant nutrients contribute to this defense. Results from intervention trials on the protective effect of the supplementation with antioxidants such as $\beta$-carotene and vitamin $E$ are not conclusive. Therefore, the beneficial effect of a high intake of fruits and vegetables on the risk of cardiovascular disease and cancer may rely not on the effect of the well-characterized antioxidants, such as vitamin $\mathrm{E}$ and $\mathrm{C}$ and $\beta$-carotene, but rather on some other antioxidants or non-antioxidant phytochemicals or by an additive action of different compounds present in foods such as $\alpha$-linolenic acid, various phenolic compounds and fiber.

Various methods have been developed to measure total antioxidant capacity or activity, such as the oxygen radical absorbance assay (ORAC), or the 2,2-diphenyl-1-picrylhydrazyl ( $\mathrm{DPPH}^{\circ}$ ) free radical assay which measures the antiradical power (ARP): the higher the ARP, the more efficient the antioxidant. In general, more than $80 \%$ of the total antioxidant capacity in fruits and vegetables comes from ingredients other than vitamin $\mathrm{C}$, indicating the presence of other potentially important antioxidants in these foods. ORAC varies considerably (20- to 30 -fold) from one kind of fruit or vegetable to another. 
As expected, the majority of studies have been carried out in cultivated fruits and vegetables. Brussel sprouts are one of the vegetables that show high ORAC activity. Garlic, kale and spinach are particularly high, as are strawberries and plums.

Flavonoids and other phenolic compounds appear to be antioxidants that contribute to the high antioxidant capacity observed in certain fruits and vegetables. There are several thousand different flavonoids present in plants, and many of them have antioxidant activities. The antioxidant capacities, measured as ORAC of some flavonoids, were found to be several times stronger on the basis of molar concentration than vitamins E and C. Such phenolic compounds have already been implicated as playing a role in the protection that fruits and vegetables have against chronic diseases. But the extent to which these potentially important antioxidants can be absorbed is not clear, although early evidence indicates that substantial quantities of the flavonoids are absorbed. For example, absorption of quercetin (a common flavonoid) defined as oral intake minus ileostomy excretion and corrected for degradation within the ileostomy bag was $52 \pm 15 \%$ for quercetin glucerides from onions.

The importance of the antioxidant and $\alpha$-linolenic constituents of plant materials in the maintenance of health and protection from coronary heart disease and cancer is raising interest among scientists, physicians, food manufacturers and consumers as the trend of the future is moving towards functional foods with specific health effects. Flavonoids and other phenolics have been suggested to play a preventive role in the development of cancer and coronary heart disease. Ingestion of alcohol-free red wine or a phenolic compound mixture extracted from red wine has been shown to improve the antioxidant status of plasma in humans. The antioxidant activity of phenolics is mainly due to their redox properties, which allow them to act as reducing agents, hydrogen donors and singlet oxygen quenchers. They also have a metal chelation potential.

In addition to their antioxidant activities, wild plants are also storehouses of essential fatty acids - especially $\alpha$-linolenic acid - and micronutrients such as calcium, phosphorus, potassium, magnesium, zinc, copper and iron. In developing countries, micronutrient deficiencies are a significant health problem, particularly for maternal, infant and child health. The use of indigenous green leafy vegetables has been used to correct these deficiencies with great success.

The chapters in this volume provide scientific evidence for the important contributions to health of wild plants for both developed and developing countries. The antioxidant components contribute to decreased risk for chronic diseases and the micronutrients to decreased risk for nutritional deficiencies. Implementation of scientific discoveries is an essential component in improving nutrition policy. The first five chapters provide data on the nutritional composition of indigenous plants from Crete (Greece) and North Africa, India, Thailand, 
and Central, South America and the Caribbean. The sixth chapter is on nutrition policy to combat micronutrient deficiency through indigenous foods instead of synthetic vitamins.

In the last two decades a number of scientists have studied the composition of wild plants as good sources of natural antioxidants, because of a trend towards natural ingredients in food. It was therefore important to investigate the antioxidant and $\omega-3$ fatty acid composition of diets such as the diet of Crete that has been shown to be associated with a decreased rate of cardiovascular disease and cancer. Wild plants have contributed to the diet of both humans and animals since their first appearance on planet Earth. Human beings ate a variety of wild plants, whereas today the diet of developed societies is limited to a few cultivated vegetables. However, Mediterranean diets and in particular the diet of Crete is rich in edible wild plants. This diet may be a reference standard for modern human nutrition and a model for defense against certain diseases of affluence. The first chapter on 'Nutritional Composition of Molokhia (Corchorus olitorius) and Stamnagathi (Cichorium spinosum)' by Zeghichi, Kallithraka and Simopoulos describes the nutritional composition of molokhia (C. olitorius), a commonly eaten wild cultivated plant in North Africa and the Middle East, and stamnagathi (C. spinosum), an edible wild plant indigenous to Crete. Antioxidants (vitamin $\mathrm{C}, \beta$-carotene, $\alpha$-tocopherol, glutathione and phenols), antioxidant activity, minerals (K, Na, $\mathrm{Ca}, \mathrm{Mg}, \mathrm{Fe}, \mathrm{Cu}, \mathrm{Mn}, \mathrm{Zn}$ and $\mathrm{P}$ ) and fatty acid composition were determined during plant growth. The seeds were harvested from wild plants and grown in the green house at $25^{\circ} \mathrm{C}$. Leaves were harvested for extraction every 5 or 10 days. The results showed that both plants contained considerable amounts of antioxidants especially molokhia, which reached levels of 77.42 and 14.89 , and $38 \mathrm{mg} / 100 \mathrm{~g}$ wet weight of vitamin C, $\alpha$-tocopherol and phenols respectively. The glutathione content also increased during leaf development (12.52 and $13.77 \mathrm{mg} / 100 \mathrm{~g}$ wet weight for molokhia and stamnagathi respectively). In addition, molokhia is rich in $\mathrm{Ca}, \mathrm{Cu}$ and $\mathrm{Mn}$ while stamanagathi is a source of $\mathrm{Fe}, \mathrm{Zn}, \mathrm{K}$ and $\mathrm{Mg}$. Both plants contained $\alpha$-linolenic acid in moderate quantities $(62.14 \mathrm{mg} / 100 \mathrm{~g}$ wet weight for molokhia and $44.4 \mathrm{mg} / 100 \mathrm{~g}$ wet weight for stamnagathi). These two plants are easy to grow and could be part of agricultural development.

The second chapter on the 'Nutritional Composition of Selected Wild Plants in the Diet of Crete' by Zeghichi, Kallithraka, Simopoulos and Kypriotakis describes the nutritional composition of 25 most common edible wild plants in Crete. $\alpha$-Tocopherol, total phenols, nitrates and minerals $(\mathrm{K}, \mathrm{Na}, \mathrm{Ca}, \mathrm{Mg}, \mathrm{Fe}, \mathrm{Cu}$, $\mathrm{Mn}, \mathrm{Zn}$ and $\mathrm{P}$ ) as well as total antioxidant activity were determined. The plants were harvested from the wild fields from Heraklio in the North of Crete, Greece. The results showed that all the plants contained considerable amounts of antioxidants and minerals. Of particular interest is the nutritional composition of the 
algae, Stypocaulon scoparium. The $\alpha$-tocopherol content could not be detected and the phenols were low, but the algae had one of the highest antioxidant activities, indicating the presence of other antioxidants. Furthermore, it had the highest amounts of potassium, sodium, calcium and magnesium. This group of the 25 most commonly eaten wild plants provides all the necessary micronutrients in more than adequate amounts, whereas the micronutrient content of the cultivated plants has decreased significantly over the last $50-70$ years. There is evidence from other studies that the nutrient content of our food supply is decreasing. Mayer compared the mineral content of 20 fruits and 20 vegetables from 1936 to the 1980 s, using a special methodology to ensure that comparable laboratory methods were employed. Over that 50-year period, there were statistically significant decreases of calcium, magnesium, copper and sodium in vegetables, and of manganese, iron, copper and potassium in fruits. Zinc was not studied. The magnitude of some changes was large: the copper level in vegetables in the 1980s was less than $20 \%$ of the 1936 levels. Mayer attributed these changes to the fact that agriculture relies on fertilizers containing only nitrogen, phosphorous and potassium, and there is little effort to remineralize the soil over the decades.

It is important to identify vegetable foods of high value such as leafy greens that are native to a region and establish their nutritional profile. This is particularly relevant to tribal belts of India where a variety of leafy vegetables are grown for household consumption in their backyards or they are picked from the wild, but these are not commercially exploited, as they are not sold in the market. The leaves could well be a repository of important microconstituents that can provide nutritional support and optimize health and wellbeing with a potential for world agriculture.

The third chapter on 'Kanjero (Digera arvensis) and Drumstick Leaves (Moringa oleifera): Nutrient Profile and Potential for Human Consumption' is by Seshardri and Nambiar. The authors present their study on the nutritional composition of the green leaves of kanjero and drumstick, and their use in increasing the vitamin A content of the diet. The intervention study showed that the bioavailability of $\beta$-carotene from fresh and dehydrated drumstick leaves compared favorably with the bioavailability of synthetic vitamin A. These results support the hypothesis that plant sources are effective in correcting vitamin A deficiency. Overall, drumstick leaves emerged as superior, containing the highest level of the two antioxidant nutrients, $\beta$-carotene and ascorbic acid, and as well as having the highest level of carotenoid pigments compared to either kanjero or the commonly consumed leafy vegetables such as spinach or fenugreek leaves. Drumstick leaves also had the highest level of ascorbic acid. The distribution of flavonoids, phenolic acids, saponins and steroids in kanjero and drumstick leaves show that the flavonoids of kanjero species are quercetin and the major phenolic acids are vanillic and syringic acid. 
The fourth chapter is on 'Ivy Gourd (Coccinia grandis Voigt, Coccinia cordifolia, Coccinia indica) in Human Nutrition and Traditional Applications' by Wasantwisut and Viriyapanich. In Thailand, ivy gourd is a common vegetable in the village setting, whereas in Western Australia, the Pacific Islands and Hawaii, ivy gourd is labeled as a common weed or invasive weed, which is destroyed. Ivy gourd is rich in $\beta$-carotene, a major precursor of vitamin A from plant sources, also a good source of protein, fiber and a moderate source of calcium, and compares well to other commonly eaten vegetables, i.e., Chinese cabbage, amaranth, kale, pumpkin leaves and chayote leaves. In many developing countries where vitamin A deficiency is prevalent, the population depends primarily on plant sources to obtain vitamin A from their diet. In Thailand, because ivy gourd is rich in $\beta$-carotene, readily acceptable for consumption by all age groups, inexpensive as well as accessible to the village households, this plant was selected in several studies to demonstrate an effect of dietary intervention to improve vitamin A nutrition.

The fifth chapter is on 'Acerola (Malpighia glabra L., M. punicifolia L., M. emarginata D.C.): Agriculture, Production and Nutrition' by Johnson. Acerola has been known historically as a concentrated source of natural ascorbic acid. Juice from acerola cherries is useful for fortifying the ascorbic acid content of other fruit juices. It has been used as a commercial source of vitamin C in dietary supplements as well as other food products. A shrub or small tree has been cultivated as an ornamental in subtropical areas where it flowers from April to November. Ascorbic acid from natural sources such as acerola is more readily absorbed by the human body than that which is synthetically produced. The vitamin $\mathrm{C}$ of acerola powder was found to be 1.63 times more bioavailable to humans in a double-blind study than USP vitamin C. In addition to ascorbic acid, acerola is a source of vitamin A, iron, calcium, potassium and vitamin B, and enhances the antioxidant activity of other botanical extracts, i.e. in the presence of acerola cherry extract, soy and alfalfa phytoestrogen extracts prevent the oxidation of LDL. The vitamin C content of the fresh fruit begins to decrease as soon as $4 \mathrm{~h}$ after harvest.

The uniquely high vitamin $\mathrm{C}$ content of the acerola, in addition to its many potential uses for processed acerola products, make this plant valuable for further utilization in food products. Since much of the nutritional value of acerola fruits can be 'fixed' through a variety of processing methods, the acerola continues to be of great value when prepared as single-entity products or when combined as a healthy additive to multi-ingredient blends. Research into other health benefits offered by acerola (in addition to vitamin $\mathrm{C}$ supplementation) indicate that the use of botanical products offers potentially superior results when compared to the use of isolated synthetic compounds. The limited market potential of fresh acerola fruit presents opportunities for the development of 
varieties, cultivation and harvest practices, as well as storage and handling methods that can improve the characteristics of the fresh fruit. The pleasant taste of ripe acerola, in addition to health benefits derived from its consumption, make fresh acerola a worthy challenge for the agricultural community.

Because wild plants supply a significant portion of micronutrients to the diet and exhibit higher mineral values than more accessible, cultivated alternatives, substantial economic and nutritional gains could be achieved by increasing dietary utilization of edible wild plants. However, lack of compositional data continues to be a limiting factor when attempting to evaluate the role of wild food plants in contemporary diets. Edible wild plants are part of agricultural systems in Africa, Asia, Australia, the Americas or Europe. Agricultural development should not be at the expense of nutritional quality of the human diet where edible wild species play critical roles. The nutritional quality of diet may decline with agricultural development unless edible wild species that provide essential micronutrients to the diet are considered part of the total food system. We and others have documented that some edible wild plants not only augment the human diet, but that the nutritional content of some wild species is superior in vitamin and mineral content to widely raised domesticated field crops. Furthermore, edible wild plants are regular components of the diets of millions of people and scientists over the past 50 years have continued to stress the importance of edible wild plants as part of the human diet.

Gopalan and Tamber, in their chapter on 'Food-Based Approaches to Prevent and Control Micronutrient Malnutrition: Scientific Evidence and Policy Implications', emphasize biodiversity and the optimal use of plants to combat micronutrient deficiency. It is indeed possible that micronutrient deficiencies are often the result of lack of enough habitual food in the household rather than to the poor quality of such foods. Drs. Gopalan and Tamber provide good argument that a food-based rather than drug-based approach will be the proper answer to the problem of micronutrient deficiencies as indeed to the problem of undernutrition in general.

In light of modern knowledge, vegetables, fruits and nuts have emerged as the food items which could address multiple problems at both ends of the socioeconomic spectrum. Vegetables, fruits and nuts can provide the 'micronutrients' usually deficient in the diets of poor communities. They can also provide the 'phytonutrients' which help to combat the chronic diseases of the affluent. The promotion of consumption of vegetables, including green leafy vegetables and fruits in adequate quantities $(450 \mathrm{~g})$, must become a central part of the strategy for nutritional improvement of all populations. From available data it may be reasonable to argue that in a healthy state a dynamic equilibrium among different micronutrients is achieved. The actual amounts of different micronutrients involved in the establishment of this equilibrium may not be 
identical and may vary with different population groups with their overall dietary patterns. Drs. Gopalan and Tamber conclude that if the type of attention that was devoted to the improvement of wheat and rice with respect to yield, protein content and disease resistance in the wake of the Green Revolution is now devoted to the improvement of micronutrient content of plant foods, the results could be truly rewarding. They recommend:

'Plant breeding strategies directed towards: (i) increasing the concentration of minerals (iron and zinc) and vitamins ( $\beta$-carotene); (ii) reducing the amount of antinutrients such as phytic acid, and (iii) raising the sulphur containing foods which can promote the absorption of zinc, also offer possibilities of augmentation of production of micronutrient rich foods.

'International agencies will be rendering real service to developing countries by strongly propagating ways by which the bioavailability of micronutrients from horticulture plant foods available at their door steps can be improved by:

1. Improved cooking and processing procedures

2. Better preservation techniques that could increase availability throughout the year

3. Home-processing techniques to reduce inhibitors of absorption

4. Simple methods of achieving enzymatic hydrolysis of phytates in cereals and legumes through fermentation and germination

5. Promoting non-enzymatic methods of reducing phytic acid content

6. Invoking home processing techniques like malting, avoidance of drinking of tea and coffee with the meal, reducing the use of tamarind (rich source of tamarind) as a souring agent and instead use tomato or lime juice, in order to facilitate non-haeme iron absorption.'

Plants in Human Health and Nutrition Policy should be of interest to those involved in food production, industrial and agricultural development, and sustainable agriculture, including scientists who are students of human evolution and development. Specifically, botanists, experimental biologists, agronomists, food technologists, nutritionists, pharmacologists, physicians, economists, policy-makers and anthropologists will discover their collective contribution in furthering human health and sustainable agriculture, and having a positive impact on the environment.

Artemis P. Simopoulos, MD

1 Simopoulos AP: Plants in Human Nutrition. World Rev Nutr Diet. Basel, Karger, 1995, vol 77.

2 Simopoulos AP: Metabolic Consequences of Changing Dietary Patterns. World Rev Nutr Diet Basel, Karger, 1996, vol. 79. 